\title{
IMPLEMENTATION OF THE “KINEROS" MODEL FOR ESTIMATION OF THE FLOOD PRONE TERRITORIES IN THE MALKI ISKAR RIVER BASIN
}

\author{
Mariyana NIKOLOVA, Stoyan NEDKOV, Valentin NIKOLOV, \\ I. ZUZDROV, Marin GENEV, Tzvetan KOTSEV, Rumiana \\ VATSEVA, and Yulia KRUMOVA
}

\begin{abstract}
This article presents main results from the implementation of the KINEROS model to the Malki Iskar river basin above the town of Etropole. KINEROS is a mathematical model based on fundamental physical laws aimed at simulating the spatial distribution of water balance elements for a given meteorological event. A detailed study of the set of physical geographical flood risk factors (relief, climate, waters, soils, LC/LU) has been performed. The analysis has been carried out on the basis of specific methods for estimation of the role of each factor. The results show the importance and practicality of implementation of the GIS, RS and flood risk modeling in generally unpredictable dangerous situations, which are typical for small mountain catchments. The application of the KINEROS model for simulation of events depending on the changes in the landscape conditions may increase significantly the effect of flood risk management in mountainous municipalities.
\end{abstract}

Keywords: KINEROS, GIS, RS, flood hazard modeling.

\section{Introduction}

Implementation of different models for simulation of hydrological processes and flood risks is the most modern and widely applied approach to the management of river basin territories. No universal model exists that would generate equally reliable results for all river basins due to the significant effect of river size on the process of suitable model selection. The aim of this study is focused on the first implementation of the KINEROS model (KINematic runoff and EROSion model) in Bulgaria and on simulation of the runoff changes for different scenarios of the territorial development of the upper course of the Malki Iskar river basin. Modeling of the processes occur- 
ring in small mountain catchments represents a serious challenge due to the difficulty of meeting model requirements related to the river basin and providing the necessary data for the model. However, this modeling approach makes it possible to establish the role of the multitude of factors contributing to the formation of considerable surface runoff, high waves and floods in the basins and of outlining the specific features that have to be considered in flood risk management in relatively small mountain catchments, such as that of the Malki Iskar river above the town of Etropole. The results of this research effort could also be used for optimizing the work related to population protection against flooding in many other mountain municipalities in the country.

\section{Materials and Methods}

This study has been carried out on the basis of a complex geographical approach to estimating the conditions and relationships between the environmental factors, which are considered to be the most important for determining the degree of flood hazard in the investigated mountain region. The methods of mathematical modeling by KINEROS and the conventional cartographic and statistical methods, as well as remote sensing and terrain investigation have been applied for this purpose.

KINEROS is a mathematical model based on fundamental physical laws aimed at simulating the spatial distribution of water balance elements for a given meteorological event. It is suitable for modeling the processes of interception, infiltration, surface runoff and erosion for relatively small (up to $100 \mathrm{~km}^{2}$ ) river basins characterized by predominating surface runoff. The watershed is conceptualized as a cascade of planes and channels, over which flows are routed in a top-down approach using a finite difference solution of the one dimensional kinematic wave equations. KINEROS could be used to evaluate the effect of various artificial features such as urban development, detention reservoirs, circular conduits, or lined channels on flood hydrograph and sediment yield. ${ }^{1}$ The model consists of five basic modules: 1 ) surface runoff from the Earth's surface; 2) surface runoff from water flows; 3) infiltration; 4) erosion and solid runoff; 5) interpolation of precipitation and interception.

The implementation of the model in a GIS environment has been realized by means of the AGWA software (Automated Geospatial Assessment Tool), which facilitates parameterization and calibration of the model. It represents a multifunctional system designed to: 1) ensure a simple, direct and reproducible method for hydrologic modeling; 2) use basic and easily accessible GIS data; 3 ) be compatible with other GIS tools for spatial analysis on catchment level; and 4) ensure the possibility of composing scenarios stimulating the future development of a given territory for different scale of investigation. ${ }^{2}$ AGWA operates as an application for one of the widely used GIS software - ArcView 3x, and the newest version is compatible with ArcGIS 9x. 
Information about all environmental components has been used for carrying out the investigation taking into account the model requirements, namely: a digital elevation model, SRTM (the Shuttle Radar Topography Mission) with resolution of 90 m, Map of World Soil Resources, Map of Soils in Bulgaria, CORINE Land Cover (CLC1990 and CLC 2000) database and Landsat ETM+ satellite images. Other used materials are: topographic maps and materials from the National Geofund; hydrologic information about the high waves that have passed through the section of HMS 108 and 107 during the period 1995-2005; meteorological information from rain gauge station No.64420, Etropole; meteorological data from the automatic meteorological station in the "Elatsite" mine for the period 2004-2007; data from measurements made during the terrain investigation; synoptic information for the meteorological factors that have created conditions for abundant precipitation leading to high wave formation during the period 1995-2005; data about the Etropole State Forestry; data about the flood damages in the region from the Civil Protection Agency and the Etropole municipality and data and materials from the terrain investigations.

\section{Study Area}

The study area is selected according to the following criteria meeting the requirements of the model: 1) to comprise small catchments with an area of up to $100 \mathrm{~km}^{2}$; 2) runoff formation under natural conditions; and 3) available hydrometric station. The Malki Iskar river basin above the town of Etropole corresponds to a high degree to the above conditions and has the following characteristics within the boundaries outlined in Figure 1: area $-196 \mathrm{~km}^{2}$; average altitude of the Etropole kettle $-545 \mathrm{~m}$; average altitude of the Malki Iskar river basin, town of Etropole $-1164 \mathrm{~m}$, and altitude of the Ravna river basin, Boykovets village $-1098 \mathrm{~m}$. The area of the Malki Iskar river catchment affiliated to the Etropole hydrometric station (No.18550, (108)) is $54.3 \mathrm{~km}^{2}$, and the area of the test section of the Ravna river affiliated to the Boykovets village hydrometric station (No.18150, (107)) is $21.2 \mathrm{~km}^{2} .3$

The biggest settlement in the region of investigation is the town of Etropole, a municipal centre with 11840 inhabitants, unfavorable age structure and negative natural growth. The other settlements are Boykovets village, situated in the valley widening of the Ravna river and the Kobilya hamlet along the homonymous river course. The share of the industrial enterprises in the economic sector in 2003 is $73 \%$ and they provide $57.3 \%$ of the workplaces in the municipality. The agriculture is dominated by stock breeding. The agricultural lands occupy $9.5 \%$ of the investigated region, $0.9 \%$ of them being pastures. The forest fund covers $84.1 \%$ of the studied region and is managed by the Etropole State Forestry. The main tree species are beech, oak and hornbeam. According to data of the municipality, the wood output within its boundaries has been drastically increased in the course of the last 7-8 years - from $12000 \mathrm{~m}^{3}$ 


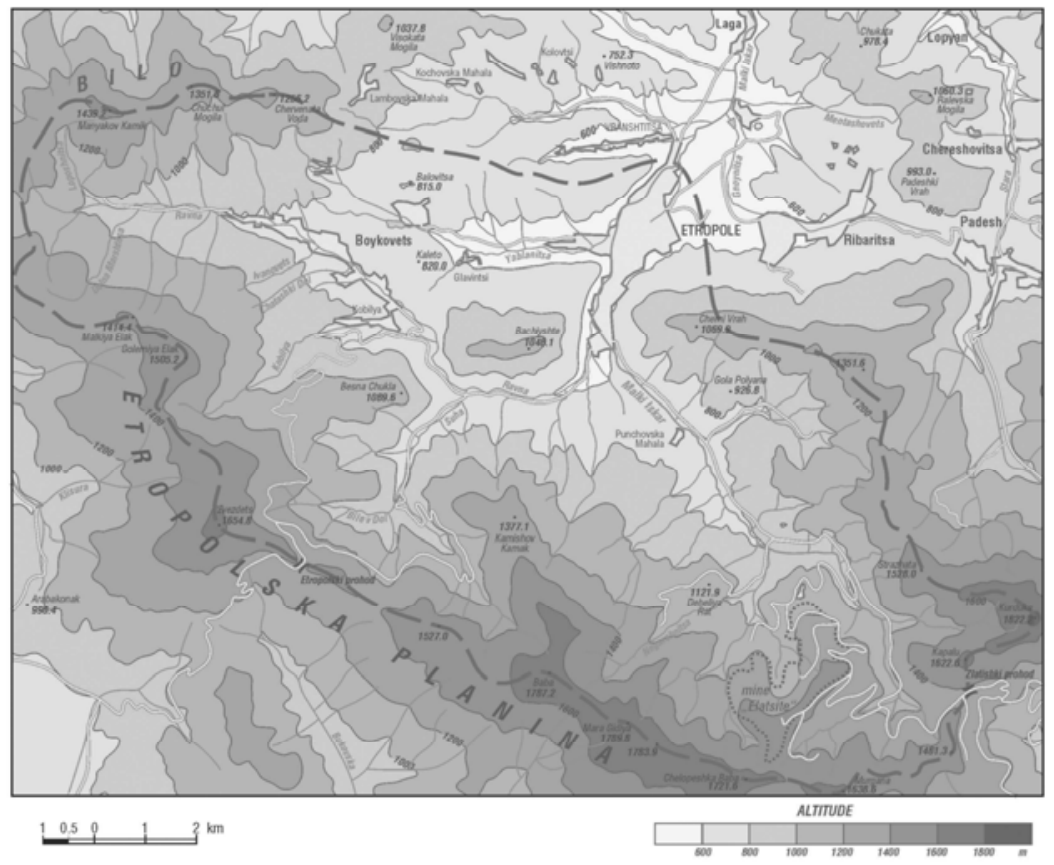

Figure 1: Study Area.

to $35000 \mathrm{~m}^{3}$ annually. Beech forests with an age of 100-150 years were fallen. As a result, during the flood in 2005 the high wave reached the town within approximately an hour. The plan for municipal development till 2013 envisages development of tourism on the basis of the nine protected territories and the numerous cultural-historical sightseeing sites.

\section{Boundaries and Relief}

The catchment of the upper course of the Malki Iskar river is formed on the territory of the Etropole Mountain. It occupies the easternmost part of the West Stara Planina Mt. Numerous steep ridges fall down from the central Stara Planina ridge, which dismember the relief of the Stara Planina slopes and contribute to the increased share of surface runoff in recharging the rivers. The share of the unstable runoff component for the Stara Planina altitude belt, which is formed mainly by the surface runoff, amounts to $52.52 \%$. The development of the midstream network, gathering a great part of the surface runoff along the slopes of the Etropole Mt., is expressed by intensive vertical (deep) and lateral erosion. The component mid-streams of the main river 


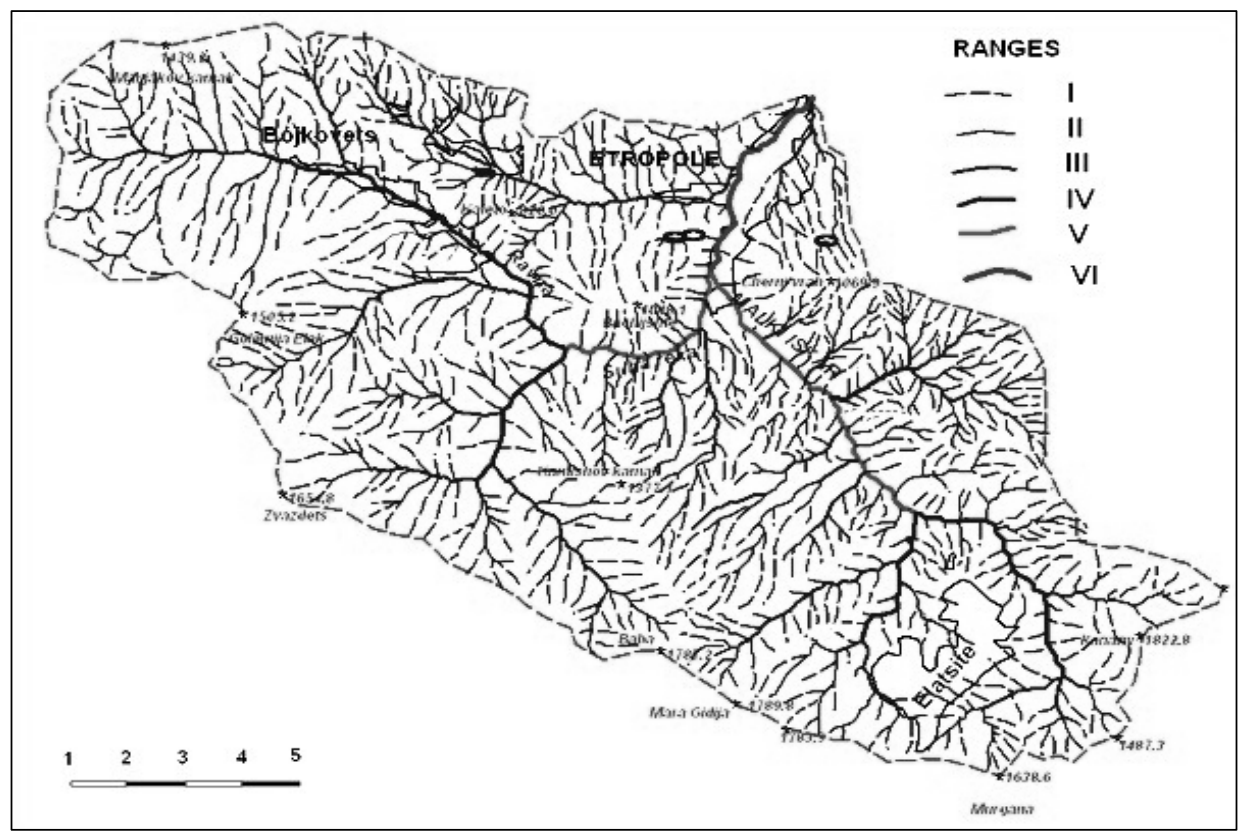

Figure 2: Ranks of the River-valley Network.

are basically of the $1^{\text {st }}, 2^{\text {nd }}$ and $3^{\text {rd }}$ rank according to the scheme of Horton, which is typical for mountain relief (Figure 2). The first rank components have narrow or short valleys in the foot of the mountain ridges or represent transitional forms of surface or linear erosion of the gully or ravine type. The transition from such temporary flows into permanent ones depends strongly on the hydro-climatic conditions and not so much on the geological-geomorphologic ones. The total erosion dismemberment is diminished in the valley expansions near the town of Etropole and the Boykovets village, while the sedimentation processes are prevalent there. In combination with the gorge sections of the river valleys, prerequisites exist in these local erosion bases for intensive sediment accumulation, especially during flood time.

\section{Climate and Waters}

The rugged mountain relief and the slope exposition of the Etropole mountain with respect to the predominant direction of atmospheric mass movement in the studied region are prerequisites for intensive precipitation during inrush of moist air masses from north-northwest during the warm half-year and for sudden rapid snow thawing due to the well expressed foehn effect along the northern mountain slopes during inrush of air masses from south-southeast during the cold season. In both cases, conditions are created for considerable surface runoff, which is capable of forming river 


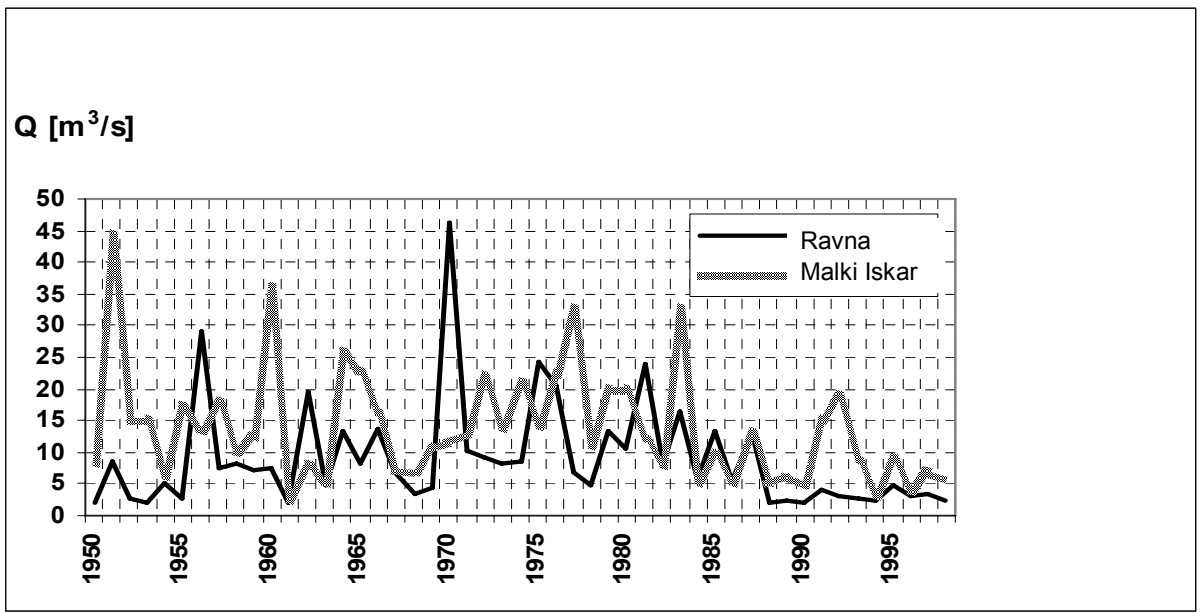

Figure 3: Maximum Runoff (Q m³/s) of the Ravna and Malki Iskar Rivers (1950-1999).

swelling and floods within a very short time. The synoptic conditions for abundant precipitation and high-wave formation are observed most often in cases of orographic occlusion along a cold front and passing of Mediterranean cyclones to the south of the country.

Due to the mountainous character of the region the extreme precipitations are intensive and most often concentrated in single parts of the catchment area. They exert more seldom simultaneous effect on all the tributaries of the main river. A record daily amount of precipitation $(105 \mathrm{~mm})$ for the Etropole rain gauge station and extreme runoff quantities of the Ravna river $\left(94800 \mathrm{~m}^{3} / \mathrm{s}\right)$ were observed on August 5, 2005.

The runoff maximum of the Malki Iskar river was observed on May 25, 2005 $39850 \mathrm{~m}^{3} / \mathrm{s}$, for the daily precipitation amount on this date in the Etropole rain gauge station of $24 \mathrm{~mm}$ and according to the automatic meteorological station of the Elatsite mine $(1042 \mathrm{~m})-79.7 \mathrm{~mm}$. Almost complete absence of synchrony was observed for the time of high-wave formation in the Malki Iskar river above Etropole and in the basin of its biggest tributary above the town - the Suha Reka river. The data show that this is a permanent trend observed during the last 55 years with best manifestation during the floods in 2005 (Figure 3).

\section{Soils and Land Cover}

The soil cover and land use are factors of primary importance for investigating the effect of landscape conditions on surface. ${ }^{4}$ In both test basins — of the Ravna and Malki 
Iskar rivers - three soil orders, five soil types and seven soil sub-types are distinguished according to the Map of Soil Diversity. The most widely developed soils are the rankers $(38 \%)$ and the unsaturated brown soils $(29 \%)$. The surface runoff formation on a given territory is also influenced to a significant extent by the mechanical composition of the surface soil horizons. ${ }^{5}$ The soils with slightly sandy-clayey to medium sandy-clayey mechanical composition (78\%) are dominating in the studied part of the Malki Iskar river catchment. The ordinary lessivated soils with heavy sandyclayey to clayey mechanical composition are situated in the lower part of the basin.

The standard CLC 2000 databases for the land cover and land use in the investigated region do not provide sufficiently detailed information for the modeling purposes. For this reason, additional interpretation has been made of Landsat ETM+ and SPOT 5 satellite images for the Ravna test site. Revised and amended database for the land cover and land use has been created using the CORINE Land Cover nomenclature. ${ }^{6}$ This revised and amended database is applied in the KINEROS model. The spatial distribution and the quantitative characteristics of the represented land cover classes show that the forests and semi-natural areas are dominant on $84.1 \%$ of the studied territory. The database with the set of just considered physical geographic factors for river swelling and flood formation has been introduced into the model.

\section{Results}

First, sub-basins in the Malki Iskar river catchment above the town of Etropole have been determined and two test catchment areas have been selected - the Malki Iskar and Ravna river ones (Figure 4). They are determined based on the location of the hydro-meteorological stations, for which data about the runoff are available, so that it is possible to make a comparison with simulated results when changes in the measured values occur.

Second, the structure of test catchment basins has been outlined. As a result of the performed spatial modeling, quantitative characteristics are obtained for the structure of the studied catchment basin of the Ravna river. It is divided into 65 plane and 27 channel model elements. A number of parameters necessary for modeling of hydrologic processes in the landscape have been calculated for each of them. The most important ones are slope inclination, ruggedness coefficient, percentage of water impermeable surfaces, interception (capacity of vegetation to capture part of the precipitation, which is evaporated in consequence), mechanical composition of soil and coefficient of hydraulic permeability related to it. The average slope inclinations of the model elements vary from 5 to 45 degrees and the percentage of the water impermeable surfaces is the highest in the valley expansion where the Boykovets village is located. 


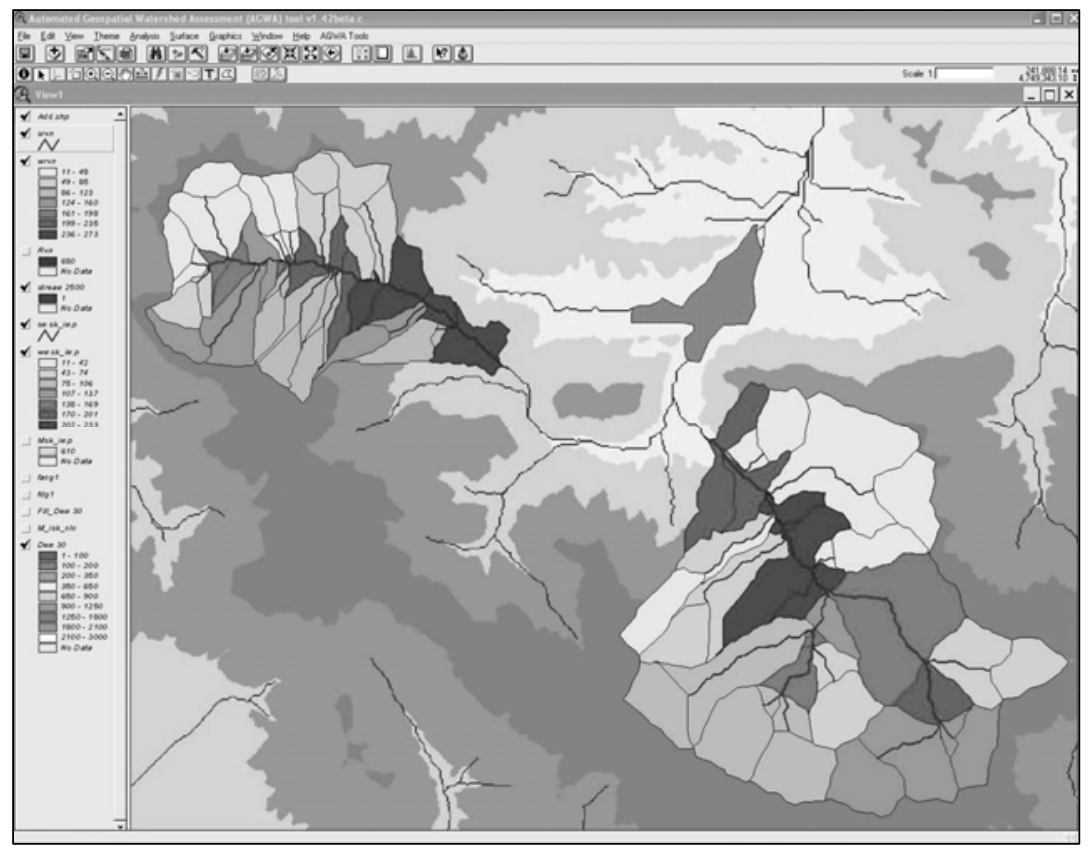

Figure 4: Differentiation of the Test Basins into Model Elements Using AGWA.

Third, analysis of the runoff in the basin on the basis of real cases of river swelling has been performed and the critical sections in the river basins and the affiliated settlements have been determined. The event of May 9, 2001, which had led to a high wave for precipitation of $25 \mathrm{~mm}$ in the course of 6 hours, has been simulated and shown in Figure 5. It gives the amount of the maximum surface runoff for the area of each model element. In this case the soil mechanical composition is more important and it is more clayey in the eastern part of the basin, where the highest surface runoff values are observed. During the terrain investigations it became clear that these were the sections of the Chitashki Dol and Ivanchov Dol gullies in the region of the Boykovets village in the Ravna river basin.

The Malki Iskar river threatens mainly the town of Etropole because it receives the water of the Suha Reka river immediately before the town and after that, within the town boundaries, the Yablanitsa river mouths in it near the cemetery park. This is one of the fourteen critical sections in the town of Etropole, where the river overflows systematically causing damages. At this particular place where the two rivers merge, the amount of sediments is rapidly increased, which additionally raises the level and deviates the water flow. Other two especially critical sections within the town boundaries are the industrial zone and the Tabashki Bridge, where the riverbed gets 


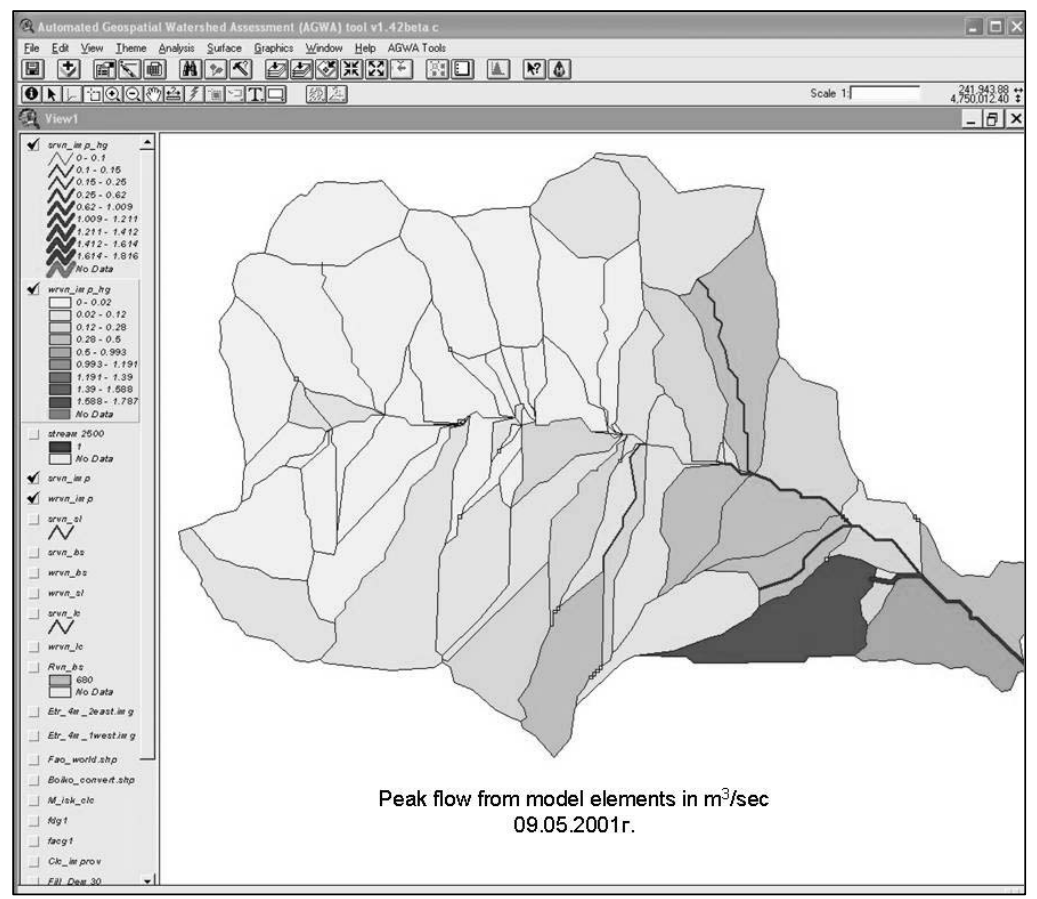

Figure 5: KINEROS Simulation Representing the Amount of Peak Flow from the Model Elements for the Hydrologic on May 9, 2001 in the Ravna River Basin.

narrower from $30 \mathrm{~m}$ before the bridge to $16 \mathrm{~m}$ immediately after it and the accelerated river flow destroys the retention walls. During the flood in 2005, 40 of them were destroyed (each of them with a length of $12 \mathrm{~m}$ and weight of 40 tons). Five of them were destroyed again in 2007. The stabilization works continue in present times, too.

Fourth, a simulation has been performed for possible cases of river swelling due to changes in the duration, amount of precipitation and/or land cover in the basins. A hypothetic event is simulated in Figure 6, where the situation is the same as that of the event on May 9, 2001, but the duration of precipitation is reduced from 6 hours to 1 hour. As a result, the maximum amount of precipitation is increased from $1.9 \mathrm{~m}^{3} / \mathrm{s}$ in the first case to $12.7 \mathrm{~m}^{3} / \mathrm{s}$ for the simulation and a part of the model elements that have no surface runoff during the former event now exhibit such runoff. The increased runoff from the streams along the right river slope is also remarkable.

In the simulation presented in Figure 7 a part of the forests in the northwest part of the basin is transformed to the bare rocks class. A scenario is considered, where complete cutting is followed by soil erosion. As a result, the amount of the surface runoff 


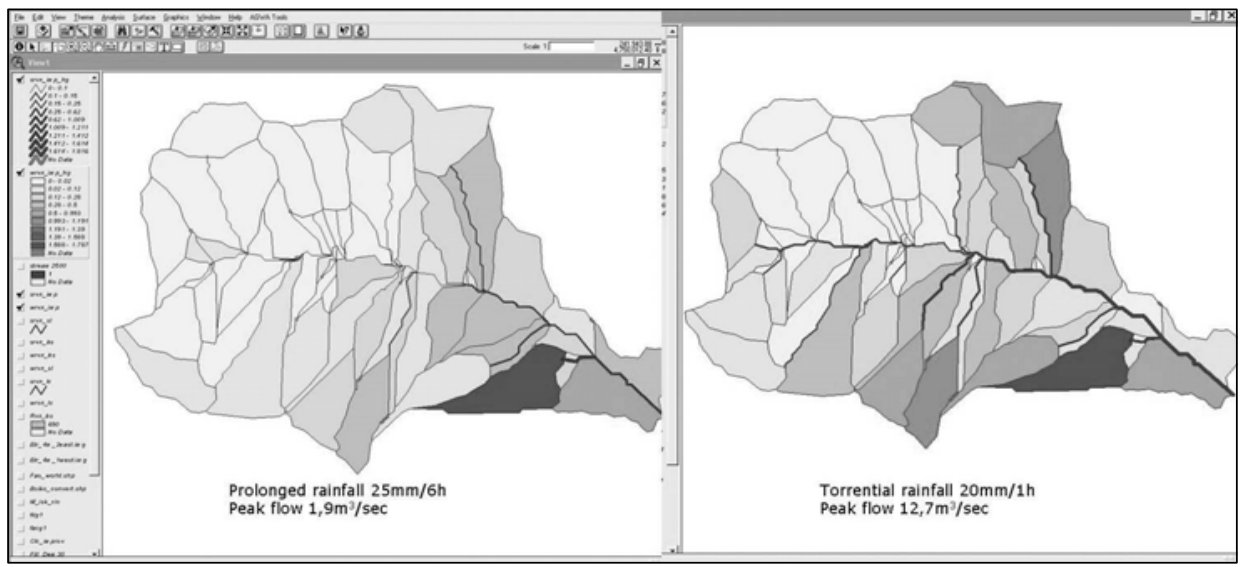

Figure 6: KINEROS Simulation Representing Differences in the Peak Flow from the Model Elements as a Result of Changes in Duration of Precipitation.

drastically increases in the model elements, where the changes have been made. High runoff growth is observed (from $12.7 \mathrm{~m}^{3} / \mathrm{s}$ to $95 \mathrm{~m}^{3} / \mathrm{s}$ ) even when only the precipitation amount is changed from $20 \mathrm{~mm}$ to $28 \mathrm{~mm}$ under the condition that the landscape is maximally water saturated. The result shows the critical value of precipitation amount and the duration of rainfall that might be expected when almost the whole precipitation amount is transformed into surface runoff.

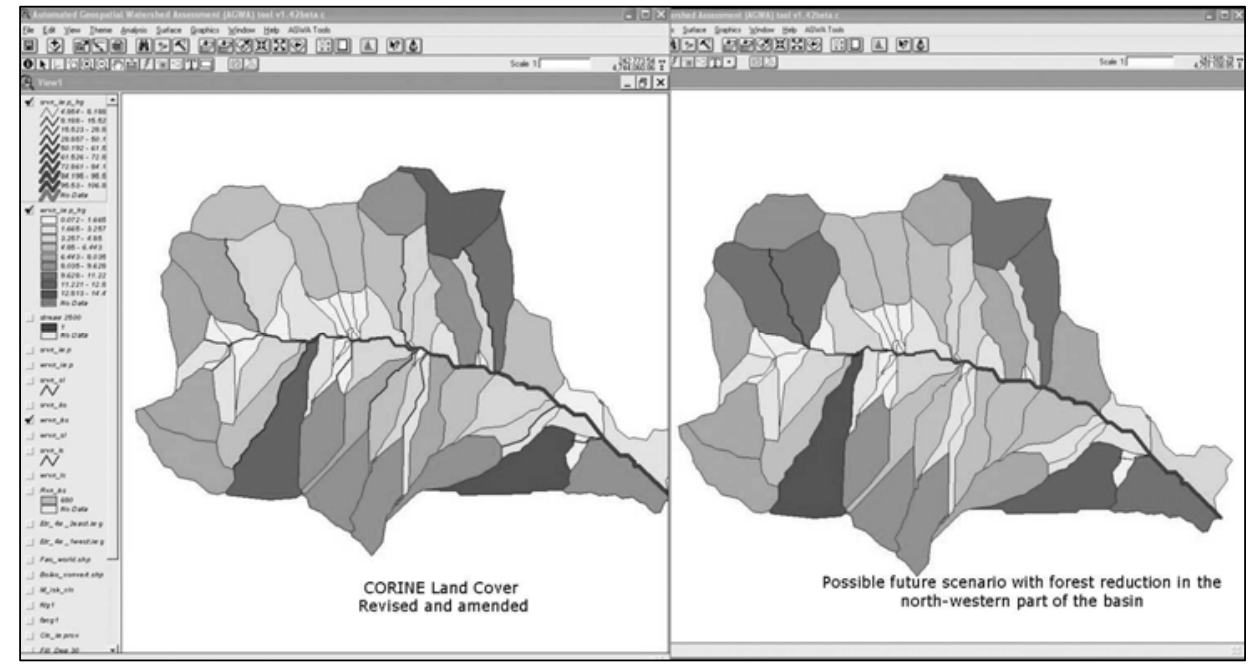

Figure 7: KINEROS Simulation Representing Differences in the Peak Flow from the Model Elements as a Result of Changes in Land Cover. 
The application of the KINEROS model for simulation of events depending on changes in the landscape conditions may increase significantly the effect of flood risk management in mountainous municipalities.

\section{Conclusions}

There are meteorological conditions and orographic prerequisites for the formation of considerable and intensive precipitation in the investigated region. Abundant precipitation and high wave formation are observed most often in case of orographic occlusion along a cold front and passing of Mediterranean cyclone to the south of Bulgaria in summer.

Due to the mountainous character of the region, the extreme precipitation is intensive; it has a "spot" character and is most often concentrated in single parts of the catchment. Simultaneous effect on the runoff of all the main river tributaries is more seldom observed.

Because of the fact that the water of the Suha Reka and Yablanitsa rivers mouth the Malki Iskar river immediately or within the boundaries of the Etropole town, the high wave effect is increased on the territory of the town, regardless of the catchment of high wave formation.

The morphographic characteristics and landscape conditions in the river basins are determinative for the formation of especially endangered by floods sections in them and for the high wave velocity in reaching the settlements.

The implementation of the KINEROS model provides the possibility of simulating the changes in river runoff amounts depending on the amount of precipitation and the land cover changes (deforestation). It may be successfully used for the management of flood risk and its accompanying hazardous phenomena (erosion) on the territory of relatively small and dangerous catchments, which are also typical for other mountain regions in the country.

The critical points during floods in the town are most often found to be by the bridges across the rivers due to inappropriate structure of some bridges, unclean riverbeds and accumulation of big amounts of sediments, which raise the level and morphology of the river bottom and often redirect the river flow.

\section{Recommendations}

Urban planning and land use on the territory of the municipality have to be in accordance to the maximum degree with the flood hazard and no construction should be allowed in the threatened zones of the town. It would be good to differentiate them as recreation zones and park spaces. Such an endangered zone is at present part of the 
industrial region of the town of Etropole, which suffers systematically from flood damages, while the stabilization of the riverbed does not produce the expected results, reconstruction works being necessary at one and the same places after each flooding.

The development of a complex monitoring of precipitation, runoff and erosion in the torrential sections of the river basins will allow the acquirement of the necessary information for modeling the processes, provoking floods, and for composing maps of the threatened territories aimed at more effective management in order to reduce and avoid damages.

Forestation and forest preservation play an extremely important role for reducing the amount and velocity of surface runoff and respectively the strength and velocity of erosion processes in the basins of the Malki Iskar and Suha Reka rivers and the related with them big sediment amounts silting the riverbeds and the bridges.

It is necessary to improve the general ecological culture of the local population and its interest in the realization of economic activities conformable to the objective natural conditions, climatic changes and risks that might ensue from them.

It is necessary that the local and state authority structures manage the territory of the country on the basis of modern scientific investigations and hazardous process modeling, when possible, so that the effect of the decisions made by them concerning the territorial management could be predicted.

It is absolutely necessary to improve and update the necessary information basis and monitoring of the environment.

The prevention activities in the studied region may reduce the flood risk but nevertheless they cannot eliminate the relevant hazard. For this reason, these activities have to be adaptive and have to include various insurance practices.

\section{Notes:}

${ }^{1}$ Darius J. Semmens, David. C. Goodrich, Carl L. Uncrich, R. Smith, David A. Woolhiser, and Scott N. Miller, "KINEROS2 and the AGWA Modeling Framework" (paper presented at the GWADI International Modeling Workshop, May, 2005), Chapter 6, UNESCO on-line publication, 30 p., <http:/gwadi.org/shortcourses/chapters/Semmens_L6.pdf $>$ (21 December 2009). 
2 Scott N. Miller, Darius J. Semmens, Ryan C. Miller, Mariano Hernandez, David C. Goodrich, W. Paul Miller, William G. Kepner, and Donald Ebert, "GIS-based Hydrologic Modeling: The Automated Geospatial Watershed Assessment Tool" (paper presented at the Second Federal Interagency Hydrologic Modeling Conference, Las Vegas, Nevada, July 28 August 1 2002).

3 Hydrologic Reference Book of the Rivers in the Republic of Bulgaria, Volume I (Hydrology and Meteorology, BAS, 1981).

4 Mariyana Nikolova, Stoyan Nedkov, Darius Semmens, and Stoyan Iankov, "Environmental Quality and Landscape Risk Assessment in Yantra River Basin, Bulgaria," in Use of Landscape Sciences for the Assessment of Environmental Security, NATO Science for Peace and Security Series C: Environmental Security, ed. Irene Petrosillo, Felix Muller, K. Bruce Jones, Giovani Zurlini, Kinga Krauze, Sergey Victorov, Bai-Lian Li, and William G. Kepner (The Netherlands: Springer, 2007), 209-224; Stoyan Nedkov and Mariyana Nikolova, "Modeling Flood Hazards in Yantra River Basin" (paper presented at the International Conference on Water Observation and Information System for Decision Support, Ohrid, May 2006), 123-139.

5 Gyuro Gyurov, "Classification of Soils in Bulgaria," in Soil Science, ed. Gyuro Gyurov and Tonko Totev (Sofia: Zemizdat, 1990), 159-267; Boris Nikolov, Manual for Laboratory Work on Soil Geography with Fundamentals of Soil Science (Sofia, 1975), 149.

${ }^{6}$ Y. Heymann, C. Steenmans, G. Croisille, and M. Bossard, CORINE Land Cover. Technical Guide (Luxembourg: Office for Official Publications of the European Communities, 1994), 136.

MARIYANA NIKOLOVA is Research Director of the Institute of Geography, Bulgarian Academy of Sciences since 2000. She graduated in geomorphology and cartography from Sofia University "St. Kliment Ohridski," Department of Geology and Geography and received a Ph.D. degree in Climatology and Agro-climatology from Institute of Geography, Bulgarian Academy of Sciences (1999). Dr. Nikolova is associate professor in the Institute of Geography, Bulgarian Academy of Sciences and visiting professor of climatology and hydrology in Shumen University "Bishop Kostantin Preslavski." Her research work is in field of physical geography, climatology, natural hazards, environmental risk assessment, environmental quality and ecological aspects of the climate change. She has more than 65 scientific publications in geography and environmental hazards and risk. Dr. Nikolova is a member of the Union of the Bulgarian Scientists, Balkan-Carpathian Geomorphologic Commission, International Geographical Union: National Geographical Committee, Commission on Natural Hazards - Chief of the Board, Specialized Geographical Scientific Council at the Ministerial Council of Republic of Bulgaria and Scientific Council of the Institute of Geography at Bulgarian Academy of Sciences. 